\title{
An Evaluation of Pulse Oximeter Modules In Capturing Photoplethysmography Signals In Order To Fabricate A Monitor To Predict Onset of Exertional Heatstroke
}

\author{
Anushka Sharma ( $\square$ as7316@ic.ac.uk) \\ Imperial College School of Medicine, Imperial College Medicine \\ Christopher Law \\ Department of Biomedical Engineering, Imperial College London \\ Choi Wan Lo \\ Department of Biomedical Engineering, Imperial College London \\ Jesse Ovia
}

Department of Biomedical Engineering, Imperial College London

Ming Hia

Department of Biomedical Engineering, Imperial College London

Papavee Phongsopa

Department of Biomedical Engineering, Imperial College London

Rory Horder

Department of Biomedical Engineering, Imperial College London

Ruijin Tang

Department of Biomedical Engineering, Imperial College London

\section{Research Article}

Keywords: medical technology, heart rate, pulse oximetry

Posted Date: June 3rd, 2021

DOl: https://doi.org/10.21203/rs.3.rs-558586/v1

License: (c) (1) This work is licensed under a Creative Commons Attribution 4.0 International License. Read Full License 


\section{Abstract}

\section{Background}

During strenuous exercise, individuals face a significant risk of developing heat-related illnesses, such as exertional heatstroke (EHS). Parameters that have demonstrated an important role in monitoring and prevention of EHS development include heart rate (HR), hydration status (determined by serum electrolyte concentrations), and core body temperature. In this study, the performance of two integrated HR monitor and pulse oximeter modules (AFE4403 from Texas Instruments and MAXIM30101 from Maxim Integrated) in capturing raw photoplethysmography (PPG) signals was evaluated during resting, exercise, and motion.

\section{Results}

PPG signals collected from a wrist-worn device using green light-emitting diodes (LED) provided good HR estimates. However, the device was not resistant to motion artefacts.

\section{Conclusion}

Further work was conducted to fabricate sensors that could measure sodium concentrations in sweat, and core body temperature from the skin. Once each sensor prototype is finalised, sensor integration could result in a device that measures three bodily parameters to a sufficient degree of accuracy in order th predict the onset of EHS. The fabrication of the other two sensors has not been described in this report.

\section{Introduction}

The sophisticated technology available today has enabled the integration of biotechnology into modern clinical practice and has created novel opportunities for advice pertaining to overall wellbeing to be delivered through virtual platforms [1]. Elegant technologies have potentiated prospects for individuals to monitor their health in the absence of clinical supervision, by quantifying physiological parameters and relaying the appropriate information to users [2]. Refined techniques have been employed to measure parameters through wearable devices, to facilitate an extended monitoring period, and to encourage compliance [3]. A common challenge that non-invasive, user-friendly health monitoring devices face, however, is obtaining measurements with both accuracy and feasibility. Another challenge is the lack of personalisation offered by these devices.

This report proposes a multimodal monitoring device comprising three sensors, that could aid the prediction and prevention of exertional heat stroke (EHS). The device would be designed to benefit exercising individuals, for whom the development of EHS is more likely, and thus the value of continuous monitoring is more pronounced.

EHS is defined as a core body temperature exceeding $40^{\circ} \mathrm{C}$, associated with neurological dysfunction [4], and is a major cause of endurance-related morbidity [5]. Milder forms of heat-related injury may predict 
eventual development of EHS [6]. However, due to the non-specific nature of the symptoms of this 'precursor state', and possible neurological impairment, an individual may be unaware of their increasing risk of EHS development without monitoring assistance [7]. Identifying individuals within the precursor state would provide a means for preventative intervention and could potentially extend the lifesaving "golden hour" treatment window in those identified in early stages of EHS manifestation [8].

The concept of a wearable technology designed to prevent EHS is not entirely original, and existing literature modelled our expectations when building a suitable device. Lin et al. described a device that measured HR, body temperature, environmental temperature and humidity; the device comprised a wearable component, wireless transmission and a back-end monitoring system (to analyse heatstroke risk), and employed corrective filtering algorithms [9]. Gao et al. measured concentrations of glucose, lactate, sodium and potassium in the sweat; this mechanically flexible and fully integrated sensor array for multiplex in situ perspiration was fabricated as a 'smart wristband' with a wireless, flexible printed circuit board component [10]. Wu et al. went on to include measurements of sweat $\mathrm{pH}$; this was achieved by an antimony ion-selective electrode. However, the report lacked detail regarding the roles that sweat $\mathrm{pH}$ and skin temperature measurements play in a health-related setting [11].

Several measurable parameters were deliberated in the early stages of the research. The parameters eventually chosen included photoplethysmography (PPG), sweat sodium concentration and core body temperature. Parameters were selected on the basis that they could be measured non-invasively and are implicated in one's risk of EHS development. In this report, the evaluation of different heart rate (HR) and pulse oximetry modules is described in detail, as is an area of vast interest in research pertaining to wearable technology. The other elements to the device (measurement of sweat electrolyte concentrations and body temperature) have not been reported. PPG is a non-invasive, optical method for detecting changes in blood volume in living tissue. It allows for the instantaneous computation of both heart rate and peripheral perfusion index. EHS itself develops due to loss of the normal thermoregulatory response, exacerbation of systemic inflammatory responses, and altered expression of heat shock proteins during heat stress. This results in a range of abnormal physiological responses, summarised in Fig. 1 [12]. This pathological process involves changes in cardiac output and tissue perfusion, and thus monitoring of these processes using PPG is beneficial when assessing one's risk of EHS.

\section{Methods}

\section{$\underline{\text { Device construction }}$}

The performance of two integrated HR monitor and pulse oximeter modules AFE4403 (Texas Instruments) and MAXIM30101 (Maxim Integrated) was evaluated using their respective evaluation modules AFE4403EVM (Texas Instruments) and MAXIM30101ACCEVKIT (Maxim Integrated) respectively. The two different sensor systems were utilised to capture the raw PPG signals. The sensor configurations used for each system are shown in Table 1. 
Table 1

Summary of sensor configurations used for capturing of PPG data. Separate sensor boards NJL5310R and SPH7050 from the AFE4403EVM were used to capture each of Green and Red LED channels respectively. The MAX30101ACCEVKIT contains a daughter board comprising multi-channel optical, motion and thermal sensing modules, which was configured to capture data from both Green and IR LEDs simultaneously. Abbreviations: LED - light emitting diode; PD - photodetector; NJRC - New Japan Radio Co.; IR - infrared; MEMS - micro electromechanical system.

\begin{tabular}{|lll|}
\hline Sensor System & Sensor & $\begin{array}{c}\text { Sampling } \\
\text { Frequency }\end{array}$ \\
\hline AFE4403EVM & NJL5310R (Green LED/PD; NJRC) & $500 \mathrm{~Hz}$ \\
\cline { 2 - 4 } & SPH7050 (Red LED/PD; OSRAM) & \\
\hline MAX30101ACCEVKIT & $\begin{array}{l}\text { MAX30101 Integrated Optical Sensor (Green and IR } \\
\text { LED/PD; Maxim Integrated) }\end{array}$ & $100 \mathrm{~Hz}$ \\
\hline LIS2DH (3-axis MEMS Accelerometer; ST Microelectronics) & \\
\hline
\end{tabular}

A case for the MAX30101 sensor system was designed in SOLIDWORKS and printed using a Prusa I3 MK3 3D printer with Verbatim PET-G transparent filament. The MAX30101DBEVKIT daughter board was housed in the bottom half of the case (Fig. 2) while the USBOSMB mother board was housed in the upper half of the case (Fig. 3).

\section{Data Acquisition}

Signals from the AFE4403EVM and the MAX30101ACCEVKIT were captured using the AFE4403EVM GUI and MAX30101 EV Kit Software respectively. Prior to data acquisition, the AFE4403EVM was calibrated using the in-built calibration routine in the AFE4403EVM GUI. The various sensor positions tested are shown in Fig. 4. All data processing was carried out in MATLAB R2019a.

Signal Properties

To calculate the signal-to-noise ratio (SNR) of the collected PPG signals, the clean PPG waveform was extracted by applying a bandpass filter to detrended raw PPG signals using the MATLAB function detrend and bandpass. A frequency band of 0.5 to $4 \mathrm{~Hz}$ was chosen, corresponding to the typical physiological range of HR [17]. The clean PPG waveform was composed of the fundamental HR component as well as its harmonics. The noise component of the waveform was obtained by applying a highpass filter using the MATLAB function highpass with a threshold frequency of $4 \mathrm{~Hz}$. For clarity, frequencies below $0.5 \mathrm{~Hz}$ were not considered in the computation of SNR. The collection of data is summarised in Table 2. 
Table 2

PPG signals acquired under stationary and motion conditions

\section{Type of Dataset Description \\ PPG \\ Signal}

PPG

Signals

from

Stationary

Position

(Datasets

\#1-8)
The data from this dataset comprises the raw PPG signals collected from 2 healthy male human subjects of ages 21 and 24 .

From Wrist

The subject was recorded while sitting with their arm rested on a table at chest height.

For recordings taken from the chest, the subject was recorded while sitting with breaths regulated at 1 breath (inhalation and exhalation) per 4 second. Signals were captured for a duration of 60 seconds. For the simultaneous measurements of PPG from the wrist using the AFE4403EVM and MAXIM30101ACCEVKIT, each sensor was secured to each wrist at the position described in Fig. 6 a.

\section{From Chest}

The dataset of raw PPG signals taken from the chest while stationary (Datasets \#5-8) were excluded from this study as no clean PPG signals could be obtained from the data and were thus not amenable to analysis.

PPG

Signals during

Motion (Datasets \#9-10)
The range of movements tested was adapted from a study by Zhang et al. to record signals for both periodic and non-periodic motion for a range of different arm and hand movements (Zhang et al., 2019). This included micromotions and large movements. Signals were recorded for a duration of 120 second, divided into the following segments:

1. 0-30s: Stationary

2. 31-90: Movement

3. $91-120$ : Stationary

The range of movements included are:

1. Index finger tapping (Datasets \#9-10)

2. Running arm swing (Datasets \#9-10)

3. Hand waving (horizontal) (Datasets \#9-10)

4. Hand shaking (vertical) (Dataset \#9)

5. Fist opening and closing (Dataset \#9)

6. Radial/ulnar deviation (Dataset \#9)

7. Wrist extension/flexion (Dataset \#9)

The SNR is calculated by the formula:

$S N R=20 \log \left(\frac{\text { Signal Amplitude }}{\text { Noise Amplitude }}\right)$ 


\section{Heart Rate Algorithm}

The proposed HR estimation algorithm framework is presented in Fig. 5 and was implemented by a custom MATLAB function rory(xPPG,fsPPG). The function takes in the raw PPG time series data and the sampling rate of the sensor (in $\mathrm{Hz}$ ), and outputs the estimated HR in beats per minute (bpm). The algorithm can be divided into 3 stages: noise removal, interval estimation, and HR estimation (Fig. 5). The discrete processing steps involved in each stage is outlined in Table 3.

Table 3

Processing steps in proposed HR estimation algorithm.

\begin{tabular}{|c|c|c|}
\hline Step & Method & Description \\
\hline \multirow{3}{*}{$\begin{array}{l}\text { Noise } \\
\text { Removal }\end{array}$} & BP Filter & $\begin{array}{l}\text { Raw PPG signals from sensors are filtered using a bandpass filter } \\
\text { implemented with the MATLAB function bandpass with a frequency }\end{array}$ \\
\hline & & $\begin{array}{l}\text { band of } 0.5 \text { to } 4 \mathrm{~Hz} \text {. The frequency band was chosen to extract a clean } \\
\text { PPG waveform corresponding to HR between } 30-240 \text { bpm by removing } \\
\text { random background noise and large drifts in the signal with frequencies } \\
\text { outside this threshold. }\end{array}$ \\
\hline & $\begin{array}{l}\text { MA } \\
\text { Removal }\end{array}$ & Removal or correction of PPG signals corrupted by motion artefacts \\
\hline \multirow[t]{3}{*}{$\begin{array}{l}\text { Interval } \\
\text { Estimation }\end{array}$} & $\begin{array}{l}\text { Split Data } \\
\text { into } \\
\text { Overlapping } \\
\text { Epochs }\end{array}$ & $\begin{array}{l}\text { Filtered signal is split up into } 10 \text { second epochs using a moving window } \\
\text { which overlap by } 9 \text { seconds }\end{array}$ \\
\hline & $\begin{array}{l}\text { Peak } \\
\text { Detection }\end{array}$ & $\begin{array}{l}\text { For each epoch, the MATLAB function findpeaks was implemented with } \\
\text { the threshold for 'MinPeakHeight' and 'MinPeakDistance' set at } 0 \text { and } \\
0.4^{\star} \text { fsPPG respectively to find the location of the peaks in the waveform }\end{array}$ \\
\hline & $\begin{array}{l}\text { Interval } \\
\text { Estimation }\end{array}$ & $\begin{array}{l}\text { Intervals between peaks is computed by finding the distance between } \\
\text { peaks in each epoch. The intervals are averaged to find the average } \\
\text { interval per beat for each } 10 \text { second epoch. This average will be } \\
\text { updated every second after the initial } 10 \text { second period. }\end{array}$ \\
\hline \multirow[t]{3}{*}{$\begin{array}{l}\text { HR } \\
\text { Estimation }\end{array}$} & $\begin{array}{l}\text { Determine } \\
\text { Mean HR in } \\
\text { Each Epoch }\end{array}$ & $\begin{array}{l}\text { Determine Mean HR in Each Epoch: Average interval per beat for each } \\
10 \text { second epoch used to estimate the HR in bpm by: }\end{array}$ \\
\hline & & $\widehat{H R}=\frac{60 \times f s P P G}{\text { Average Interval per Epoch }}$ \\
\hline & & $\begin{array}{l}\text { The algorithm is used to calculate an estimate for HR over } 10 \text { second } \\
\text { epochs which is updated every second to provide a continuous readout } \\
\text { of estimated HR. }\end{array}$ \\
\hline
\end{tabular}

\section{Evaluation of HR Estimation Algorithm}

The HR estimation algorithm was evaluated using external databases and raw PPG data collected in this study (Table 4). The root-mean-squared error (RMSE) between the estimated HR calculated from the HR estimation algorithm and the reference HR is calculated by the following formula: 
$R M S E=\sqrt{\frac{1}{n} \sum_{i=1}^{N}\left(\widehat{H R}-H R_{r e f}\right)^{2}}$

Table 4

Datasets for the evaluation of the proposed HR estimation algorithm.

\begin{tabular}{|c|c|}
\hline Dataset & Dataset Description \\
\hline $\begin{array}{l}\text { BIDMC Data } \\
\text { (PhysioNet) }\end{array}$ & $\begin{array}{l}\text { This dataset contains } 53 \text { recordings from critically ill patients during hospital care } \\
\text { at the Beth Israel Deaconess Medical Centre (BIDMC), Boston, MA, USA (Pimentel et } \\
\text { al., 2017) available from PhysioNet databank. This dataset was extracted from a } \\
\text { larger Medical Information Mart for Intensive Care II (MIMIC-II) dataset (Johnson et } \\
\text { al., 2016). }\end{array}$ \\
\hline $\begin{array}{l}\text { Wrist PPG } \\
\text { during } \\
\text { Exercise } \\
\text { (PhysioNet) }\end{array}$ & $\begin{array}{l}\text { This dataset contains PPG and ECG recordings from subjects performing various } \\
\text { exercises from the PhysioNet databank (Jarchi \& Casson, 2017). The HR } \\
\text { estimation algorithm was implemented on the PPG signals from the walk and run } \\
\text { data in the dataset. The R-R intervals (RRI) in the ECG signals from the walk and } \\
\text { run data were calculated using an RRI estimation algorithm developed by Dr David } \\
\text { Looney (available at https://github.com/DavidLoon/RRI-estimation) and } \\
\text { implemented in MATLAB. The HR estimation from the ECG signals was determined } \\
\text { using the same processing steps for Interval Estimation and HR estimation in the } \\
\text { HR estimation algorithm. The HR estimated from the ECG signals is taken as the } \\
\text { reference HR. }\end{array}$ \\
\hline $\begin{array}{l}\text { Simultaneous } \\
\text { Stationary } \\
\text { PPG } \\
\text { Measurements } \\
\text { (Dataset \#11) }\end{array}$ & $\begin{array}{l}\text { Simultaneous PPG measurements were taken using the AFE4403EVM and } \\
\text { MAXIM30101 ACCEVKIT following the same setup previously described for the } \\
\text { acquisition of raw PPG while stationary. The estimated HR was computed by } \\
\text { implementing the HR estimation algorithm on each PPG measurement. }\end{array}$ \\
\hline $\begin{array}{l}\text { Smartwatch } \\
\text { HR } \\
\text { Measurements } \\
\text { (Datasets } \\
\# 12-19 \text { ) }\end{array}$ & $\begin{array}{l}\text { This dataset contains the performance of the HR estimation algorithm evaluated } \\
\text { against the HR estimation capability of the Apple Watch Series } 5 \text { and the Garmin } \\
\text { Vivoactive } 3 \text { smartwatches. Due to the proprietary nature of the HR estimation } \\
\text { functionalities in the smartwatches, it is not known how the HR estimation is } \\
\text { implemented. However, it is known that both smartwatches utilize an optical HR } \\
\text { monitor with green LED/PD (Apple Inc., 2019; Garmin Ltd., n.d.). The setup for the } \\
\text { simultaneous measurement of PPG using the } \\
\text { AFE4403EVM/MAXIM30101 ACCEVKIT and the smartwatches is the same as } \\
\text { previously described for the acquisition of raw PPG while stationary. }\end{array}$ \\
\hline $\begin{array}{l}\text { PPG } \\
\text { Measurements } \\
\text { During Motion } \\
\text { (Datasets } \\
\text { \#20-21) }\end{array}$ & $\begin{array}{l}\text { The PPG measurements were taken from Datasets \#9 and \#10 and the HR } \\
\text { estimates were obtained by implementing the HR estimation algorithm on the PPG } \\
\text { measurements. The estimated HR was split into } 3 \text { segments corresponding to the } \\
\text { stationary and motion segments previously described. }\end{array}$ \\
\hline
\end{tabular}

\section{Results}

The SNR of the raw PPG signal was computed from 20 samples taken from a single participant for both green and red light each using the AFE4403EVM and presented in Table 5. An example of the raw PPG signal for each wavelength is shown in Fig. 6 and Fig. 7. 
Table 5

Comparison of SNR performance of NJL5310R (green LED/PD) and SFH7050

(red LED/PD) using the AFE4403EVM

\begin{tabular}{|lll|}
\hline LED/PD & Peak Wavelength $(\mathrm{nm})$ & SNR $(\mathrm{dB})$ \\
\hline NJL5310R, Green & 525 & $64.13 \pm 0.94$ \\
\hline SFH7050, Red & 660 & $-8.24 \pm 2.96$ \\
\hline \multicolumn{2}{|l}{ Comparison of SNR performance of PPG signal between green and LED/PD } \\
\hline
\end{tabular}

The SNR of the raw PPG signals were calculated from 3 simultaneous readings obtained from a single participant using the AFE4403EVM and MAX30101ACCEVKIT with green light and summarised in Table 6. An example of the spectrogram and the frequency spectra of the signal is shown in Fig. 8.

Table 6

Comparison of SNR performance of AFE4403EVM and MAX30101ACCEVKIT using green light.

\begin{tabular}{|llll|}
\hline Sensor System & LED/PD & Peak Wavelength(nm) & SNR \pm SE (dB) \\
\hline AFE4403EVM & NJL5310R, Green & 525 & $55.4707 \pm 6.9066$ \\
\hline MAX30101ACCEVKIT & MAX30101, Green & 537 & $38.8359 \pm 6.9954$ \\
\hline $\begin{array}{l}\text { Comparison of SNR performance of PPG signal obtained from AFE4403EVM and } \\
\text { MAX30101ACCEVKIT (on wrist) using green LED/PD }\end{array}$ & \\
\hline
\end{tabular}

The SNR of 10 raw PPG waveforms was obtained from a single participant using the MAX30101ACCEVKIT housed within a custom 3D-printed case and positioned on the anterior wrist while the participant remained stationary. The results are summarised in Table 7.

Table 7

SNR performance of MAX30101ACCEVKIT with case, using green light.

\begin{tabular}{|lllll|}
\hline Sensor System & $\begin{array}{l}\text { With } \\
\text { Case? }\end{array}$ & LED/PD & $\begin{array}{l}\text { Peak } \\
\text { Wavelength(nm) }\end{array}$ & SNR (dB) \\
\hline MAX30101ACCEVKIT & Yes & $\begin{array}{l}\text { MAX30101, } \\
\text { Green }\end{array}$ & 537 & $\begin{array}{l}51.6433 \pm \\
4.8973\end{array}$ \\
\hline $\begin{array}{l}\text { Evaluation of SNR performance of PPG signal obtained using MAX30101ACCEVKIT (on wrist) with } \\
\text { case, using green LED/PD }\end{array}$ & & \\
\hline
\end{tabular}

3 measurements of each motion type were taken using the AFE4403EVM and the MAX30101ACCEVKIT with MAX30101 for both periodic and non-periodic movements. An example of the raw PPG waveforms is provided in Fig. 9. An example of the spectrogram and the frequency spectra of the signal obtained from AFE4403EVM during periodic and non-periodic ulnar deviation is shown in Fig. 10.

The accuracy of the proposed HR estimation algorithm was tested using 53 physiological recordings of patients from BIDMC. The estimated HR was plotted against the reference HR included within the data set. Of the 53 samples, samples 40 and 41 were excluded from the calculations as the PPG and ECG 
recordings showed significant corruption of the signals. The correlation and agreement across all datapoints $(n=24070)$ contained in the 51 samples were calculated and plotted in Fig. 11.

3 simultaneous measurements were taken using the AFE4403EVM and MAX30101ACCEVKIT and the smartwatch for each condition tested (Table 8). The RMSE, standard deviation of RMSE (SD RMSE), and mean average percentage error (MAPE) for each condition is summarised in Table 8. An example of the comparison of HR estimates from our proposed algorithm and from the smartwatches is given in Fig. 12.

Table 8

Average root-mean-square error (RMSE), standard deviation of RMSE (SD RMSE), and mean absolute percentage error (MAPE) of estimated HR from raw PPG measurements taken using AFE4403EVM and MAX30101ACCEVKIT from the wrist and chest compared to estimated HR from wrist-worn smartwatches.

\begin{tabular}{|c|c|c|c|c|c|}
\hline Sensor System, LED/PD & Location & Watch & $\begin{array}{l}\text { Average } \\
\text { RMSE }\end{array}$ & $\begin{array}{l}\text { SD } \\
\text { RMSE }\end{array}$ & MAPE \\
\hline \multirow[t]{4}{*}{ AFE4403EVM, NJL5310R, Green } & \multirow[t]{2}{*}{ Wrist } & Apple & 5.63 & 6.44 & $7.28 \%$ \\
\hline & & Garmin & 3.10 & 1.59 & $3.54 \%$ \\
\hline & \multirow[t]{2}{*}{ Chest } & Apple & 10.97 & 2.25 & $12.18 \%$ \\
\hline & & Garmin & 11.30 & 3.12 & $12.02 \%$ \\
\hline \multirow{4}{*}{$\begin{array}{l}\text { MAX30101ACCEVKIT, MAX30101, } \\
\text { Green }\end{array}$} & \multirow[t]{2}{*}{ Wrist } & Apple & 4.57 & 1.48 & $5.22 \%$ \\
\hline & & Garmin & 2.85 & 0.24 & $3.03 \%$ \\
\hline & \multirow[t]{2}{*}{ Chest } & Apple & 3.37 & 0.85 & $3.28 \%$ \\
\hline & & Garmin & 4.71 & 0.78 & $5.20 \%$ \\
\hline
\end{tabular}

The HR estimation algorithm was tested using PPG signals obtained from four subjects while running and walking on a treadmill taken from the dataset "Wrist PPG during exercise" available from the PhysioNet database. The RMSE, SD RMSE, and MAPE were calculated between the estimated HR from PPG and the reference HR calculated from simultaneous ECG measurements and summarized in Table 9. The correlation and agreement across all datapoints $(n=800)$ for each exercise is plotted in Fig. 13 and Fig. 14.

Table 9

Average RMSE, SD RMSE, and MAPE calculated between estimated HR from PPG and reference HR from ECG.

\begin{tabular}{|llll|}
\hline Type of Exercise & Average RMSE & SD RMSE & MAPE \\
\hline Running & 5.63 & 6.44 & $7.28 \%$ \\
\hline Walking & 4.57 & 1.48 & $5.22 \%$ \\
\hline
\end{tabular}

Evaluation of HR estimation algorithm during exercise and motion 
The performance of the HR estimation algorithm was also tested on the raw PPG waveforms obtained using the AFE4403EVM and MAX30101ACCEVKIT on a range of movements. The results were analysed in 3 segments corresponding to the stationary and motion segments of the PPG signal measured. A summary of the variance of HR in each segment is presented in Table 10. 
Table 10

Average variance of estimated HR for stationary and motion segments for difference motion types.

\begin{tabular}{|c|c|c|c|c|c|}
\hline Sensor System, LED/PD & Periodicity & Motion & $\begin{array}{l}\text { Stationary } \\
1, \operatorname{Var}(\mathrm{HR})\end{array}$ & $\begin{array}{l}\text { Motion, } \\
\text { Var } \\
\text { (HR) }\end{array}$ & $\begin{array}{l}\text { Stationary } \\
\text { 2, Var (HR) }\end{array}$ \\
\hline \multirow{14}{*}{$\begin{array}{l}\text { AFE4403EVM, } \\
\text { NJL5310R, Green }\end{array}$} & \multirow[t]{7}{*}{ Periodic } & Finger Tapping & 25.32 & 41.92 & 6.87 \\
\hline & & Fist Clenching & 6.74 & 93.34 & 67.88 \\
\hline & & $\begin{array}{l}\text { Running Arm } \\
\text { Swing }\end{array}$ & 6.10 & 57.60 & 11.12 \\
\hline & & Hand Shaking & 12.17 & 13.12 & 15.19 \\
\hline & & Ulnar Deviation & 19.30 & 71.55 & 12.60 \\
\hline & & Hand Waving & 3.45 & 14.65 & 22.48 \\
\hline & & $\begin{array}{l}\text { Wrist } \\
\text { Extension/Flexion }\end{array}$ & 21.02 & 81.07 & 16.82 \\
\hline & \multirow{7}{*}{$\begin{array}{l}\text { Non- } \\
\text { Periodic }\end{array}$} & Finger Tapping & 9.90 & 76.48 & 0.64 \\
\hline & & Fist Clenching & 8.50 & 52.95 & 3.70 \\
\hline & & $\begin{array}{l}\text { Running Arm } \\
\text { Swing }\end{array}$ & 30.56 & 141.90 & 5.78 \\
\hline & & Hand Shaking & 16.46 & 52.00 & 8.24 \\
\hline & & Ulnar Deviation & 10.52 & 66.22 & 7.19 \\
\hline & & Hand Waving & 2.56 & 48.07 & 3.78 \\
\hline & & $\begin{array}{l}\text { Wrist } \\
\text { Extension/Flexion }\end{array}$ & 20.40 & 103.42 & 3.91 \\
\hline \multirow{6}{*}{$\begin{array}{l}\text { MAX30101ACCEVKIT, } \\
\text { MAX30101, Green }\end{array}$} & \multirow[t]{3}{*}{ Periodic } & Finger Tapping & 7.22 & 62.59 & 1.34 \\
\hline & & $\begin{array}{l}\text { Running Arm } \\
\text { Swing }\end{array}$ & 5.07 & 61.38 & 6.69 \\
\hline & & Hand Waving & 3.95 & 61.10 & 161.39 \\
\hline & \multirow{3}{*}{$\begin{array}{l}\text { Non- } \\
\text { Periodic }\end{array}$} & Finger Tapping & 10.22 & 48.52 & 9.38 \\
\hline & & $\begin{array}{l}\text { Running Arm } \\
\text { Swing }\end{array}$ & 5.43 & 83.17 & 8.16 \\
\hline & & Hand Waving & 11.48 & 97.61 & 17.67 \\
\hline
\end{tabular}

\section{Discussion}


PPG signals generated using green light resulted in a significantly higher SNR compared to red light. This result is expected as the reflectance pulsation spectrum of blood is greatest around $575 \mathrm{~nm}$ and smallest around $650 \mathrm{~nm}$. Red and infrared wavelengths of light are also known to have deeper tissue penetration, thus picks up more physiological noise such as the movement of blood or tissue beneath the sensor which are the predominant contribution to experimental noise in PPG measurements [13]. As the sensors should be able to function as part of an exercise-focused wearable device, PPG measurements using green light should be used for HR estimation.

While it has been reported that skin pigmentation affects the intensity of the reflected light in PPG measurements [13] (due to green light being more strongly absorbed by melanin compared to red light thus resulting in relatively shallower penetration into tissue $[14,15])$, this was not investigated in this study.

While the AFE4403EVM shows better performance compared to MAX30101ACCEVKIT in terms of SNR, the SNR of the MAX30101ACCEVKIT was sufficiently high enough to be amenable to HR estimation. From the spectrograms and frequency spectra of the PPG obtained using the AFE4403EVM and MAX30101ACCEVKIT (Fig. 8), the fundamental frequency of the HR and its harmonics can be clearly identified from the peaks occurring between $0-5 \mathrm{~Hz}$ and is easily distinguishable from the background noise. The periodic HR component can easily be obtained with appropriate filtering and thresholding.

Currently, it was easier to implement the MAX30101ACCEVKIT into the proposed device due to the smaller hardware size and flexible 10-pin FFC ribbon cable (compared to the DB9 to 8 pin header sensor cable for the AFE4403EVM). The MAX30101ACCEVKIT also contained an integrated accelerometer for 3-axis motion tracking, which could be used for motion artefact removal. As such, the proposed device was constructed using MAX30101ACCEVKIT as the PPG sensor.

The SNR for the MAX30101ACCEVKIT system housed within the case was found to be approximately $30 \%$ higher than without the case. This indicates that the set-up does not appear to impair signal collection and has a SNR comparable to that of the AFE4403EVM system. This increase in SNR may be due to the differences in contact pressure between the sensor and skin when securing the sensor to the wrist with and without the case. However, due to the small number of samples, it was not possible to determine the significance of this difference in SNR within this report. The effect of contact pressure on SNR could be explored in future to optimise the device design.

Voluntary motion artefacts were qualitatively observed to introduce large changes in the pulse shape, amplitude, and frequency for the ranges of periodic and non-periodic motions tested. Frequency analysis of the PPG signal obtained showed that motion artefacts resulted in noise that lied within the range of physiological frequencies $(0-5 \mathrm{~Hz})$ and obscured the frequency peaks indicating the fundamental $\mathrm{HR}$ frequency. This decreased the confidence of HR estimation.

It was also observed that movements involving the wrist had a more pronounced effect on the PPG pulse waveforms than those involving the arm. Wrist motions were likely to cause greater movement of tissues 
beneath the wrist-worn sensor compared to arm motions, and thus introduced more physiological noise than arm movements. Alternative sensor placements could be explored in the future, such as on the chest or forehead, which are prone to less ranges of voluntary movements. The thinner layers of skin and the high impedance of the skull may also result in a high SNR for reflectance-based PPG measurements taken from the forehead.

The HR estimation algorithm described in this study closely predicted the user's actual heart rate. A strong correlation between the estimated HR and the reference HR was observed, with a Pearson coefficient of $r=0.97$ and a reasonable limit of agreement of [-5.7 5.8] (Fig. 11). The estimated HR showed a slight negative bias of $0.05 \mathrm{bpm}$. The current HR estimation algorithm provides a good approximation of the actual HR when the subject remains stationary, however, the accuracy of the HR estimation is dependent on the quality (SNR, presence of MA) of the PPG signals obtained.

Furthermore, the HR estimation algorithm described in this study was comparable to smart watches. Comparison between the estimated HR using the current proposed algorithm and commercially available wrist-worn smartwatches showed that the estimated HR from the proposed algorithm was able to follow the trend of the estimated HR from the smartwatches with a small margin of error indicated by the MAPE (Table 9). The estimated HR by the Apple smartwatch appeared to be more robust against sudden large changes in HR compared to the Garmin smartwatch (Fig. 12).

HR estimated from PPG measurements taken from the chest using the AFE4403EVM were shown to have a higher percentage error against both smartwatches, while measurements taken from the chest using the MAX30101ACCEVKIT did not show large changes in percentage error compared to measurements taken from the wrist.

The HR estimation algorithm described was not robust to motion. Comparison between the estimated HR from PPG measurements against reference HR from ECG measurements in the walk and run datasets showed poor correlation and agreement, with Pearson coefficients of 0.05 and 0.13 , and broad limits of agreement of [-16 47] and [-42 24] for running and walking respectively (Fig. 13 and Fig. 14). Additionally, results of the motion tests showed that the HR estimation during the motion displayed significantly larger variance compared to the stationary segments, caused by large fluctuations in the estimated HR due to motion artefacts (Table 10).

The bandpass filter implemented in the proposed algorithm can remove high frequency noise and baseline drifts from the raw PPG signal but is unable to correct motion-induced artefacts as these tend to occur within the bandpass threshold. Numerous methods can be explored for the removal of motion artefacts from a range of movements, some of which requiring additional data input such as acceleration or multichannel PPG signals (Table 11). 
Table 11

Current methods for motion artefact detection, correction and/or removal.

\begin{tabular}{|ll|}
\hline Method & Reference \\
\hline Statistical Measures & \\
\hline Kurtosis, Shannon Entropy & (Selvaraj et al., 2011) \\
\hline Skewness, Kurtosis & (Krishnan, Natarajan \& Warren, 2010) \\
\hline Time-Frequency Analysis & \\
\hline Independent Component Analysis & (Krishnan, Natarajan \& Warren, 2010) \\
\hline Empirical Mode Decomposition & (Kim \& Yoo, 2006) \\
\hline Sparse Signal Reconstruction & (Khan et al., 2016) \\
\hline Spectral Subtraction & (Zhang, Pi \& Liu, 2015) \\
& (Zhang, 2015) \\
\hline Wigner-Ville & (Zhang, 2015) \\
\hline Wavelet Denoising & (Zhang et al., 2019) \\
\hline Variable Frequency Complex Demodulation & (Yan, Poon \& Zhang, 2005) \\
\hline Adaptive Filtering & (Lee \& Zhang, 2003) \\
\hline Kalman Filter & (Fu, Liu \& Tang, 2008) \\
\hline Least Mean Squares Filtering & (Seyedtabaii \& Seyedtabaii, 2008) \\
\hline Recursive Mean Squares Filtering & (Khan et al., 2016) \\
\hline
\end{tabular}

The current HR estimation algorithm is not optimised in terms of processing speed or complexity. The current algorithm recalculates the peak intervals for all peaks in each window, including redundant overlapping datapoints between adjacent windows. This could be modified in future such that the calculation of peak intervals is only performed on new data points. A different approach using spectral analysis (such as periodogram, short-time Fourier transform, continuous wavelet transform, sparse-signal reconstruction based spectral estimation) could be performed given that PPG waveforms are quasiperiodic. The current algorithm is also written for post signal acquisition analysis and will need to be modified for real-time signal analysis. 


\section{Conclusion}

Once final prototypes of each of the aforementioned sensors are developed, the next steps pertain predominantly to integration of the sensors, and mobile application development for data display. The challenges of integration include miniaturisation, noise reduction, resilience to motion artefacts and bodily attachment of each individual sensor; over the remainder of the project, each team will work to ease the eventual integration process, whilst simultaneously designing a suitable mobile application to accompany the device.

\section{Abbreviations}

\begin{tabular}{|ll|}
\hline BPM & Beats per minute \\
\hline EHS & Exertional heat stroke \\
\hline HR & Heart rate \\
\hline LED & Light-emitting diode \\
\hline MAPE & Mean average percentage error \\
\hline PPG & Photo plethysmography \\
\hline RMSE & Root-mean-squared error \\
\hline SD RMSE & Standard deviation of root-mean-squared error \\
\hline
\end{tabular}

\section{Declarations}

\section{Ethics approval and consent to participate}

Imperial College Research Ethics Committee (ICREC) is the College Ethics Committee which reviews health-related research involving human participants and/or their data that is undertaken by students. Given the nature of the research, no formal ethics approval was required in this particular case, in accordance with the guidance provided by ICREC.

No external participants were recruited for the research; therefore, there was no need to obtain consent from any third party.

\section{Consent for publication}

All authors provided verbal and written consent for the submission of the manuscript to BMC Biomedical Engineering.

\section{Availability of data and material}

Further data can be made available upon valid request. 


\section{Competing interests}

No authors declare any conflict of interest.

\section{Funding}

The heart rate and pulse oximeter modules were purchased by the Department of Biomedical Engineering, Imperial College London. No external funding was sourced for the remainder of the research or for publication.

\section{Authors' contributions}

All authors (Anushka Sharma, Christopher Law, Choi Wan Lo, Jesse Ovia, Ming Hia, Papavee Phongsopa, Rory Horder and Ruijin Tang) contributed equally to the construction of the research and the content of the manuscript. Anushka Sharma and Christopher Law revisited the manuscript for editing and review prior to submission.

\section{Acknowledgements}

We would like to express our gratitude to Professor Martyn Boutelle and Dr Michelle Rogers, who have guided us throughout the integration of the sensor.

\section{References}

1. Basatneh, R., Najafi, B. \& Armstrong, D.G. (2018) Health Sensors, Smart Home Devices, and the Internet of Medical Things: An Opportunity for Dramatic Improvement in Care for the Lower Extremity Complications of Diabetes. Journal of Diabetes Science and Technology. [Online] 12 (3), 577-586. Available from: doi:10.1177/1932296818768618.

2. Ray, T.R., Choi, J., Bandodkar, A.J., Krishnan, S., et al. (2019) Bio-integrated wearable systems: A comprehensive review. Chemical Reviews. [Online] 119 (8), 5461-5533. Available from: doi:10.1021/acs.chemrev.8b00573.

3. Izmailova, E.S., Wagner, J.A. \& Perakslis, E.D. (2018) Wearable Devices in Clinical Trials: Hype and Hypothesis. Clinical Pharmacology and Therapeutics. [Online] 104 (1), 42-52. Available from: doi:10.1002/cpt.966.

4. NHS England (2018) Heat Exhaustion and Heatstroke. [Online]. 2018. Available from: https://www.nhs.uk/conditions/heat-exhaustion-heatstroke/ [Accessed: 1 May 2020].

5. Yankelson, L., Sadeh, B., Gershovitz, L., Werthein, J., et al. (2014) Life-threatening events during endurance sports: Is heat stroke more prevalent than arrhythmic death? Journal of the American College of Cardiology. [Online] 64 (5), 463-469. Available from: doi:10.1016/j.jacc.2014.05.025.

6. Helman, R.S. (2019) Heatstroke. 2019. Available from https://emedicine.medscape.com/article/166320-overview [Accessed: 1 May 2020]. 
7. Mazerolle, S.M., Ruiz, R.C., Casa, D.J., Pagnotta, K.D., et al. (2011) Evidence-based practice and the recognition and treatment of exertional heat stroke, part I: A perspective from the athletic training educator. Journal of Athletic Training. [Online] 46 (5), 523-532. Available from: doi:10.4085/10626050-46.5.523.

8. Heled, Y., Rav-Acha, M., Shani, Y., Epstein, Y., et al. (2004) The “Golden Hour" for Heatstroke Treatment. Military Medicine. [Online] 169 (3), 184-186. Available from: doi:10.7205/milmed.169.3.184.

9. Lin, S.S., Lan, C.W., Hsu, H.Y. \& Chen, S.T. (2018) Data analytics of a wearable device for heat stroke detection. Sensors (Switzerland). [Online] 18 (12). Available from: doi:10.3390/s18124347.

10. Gao, W., Emaminejad, S., Nyein, H.Y.Y., Challa, S., et al. (2016) Fully integrated wearable sensor arrays for multiplexed in situ perspiration analysis. Nature. [Online] 529 (7587), 509-514. Available from: doi:10.1038/nature16521.

11. Wu, Q., Zhang, X., Tian, B., Zhang, H., et al. (2017) Wearable sweat detector device design for health monitoring and clinical diagnosis. IOP Conference Series: Earth and Environmental Science. [Online] 69 (1). Available from: doi:10.1088/1755-1315/69/1/012137.

12. Hunt, P.A.F. \& Smith, J.E. (2005) Heat illness. Journal of the Royal Army Medical Corps. [Online] 151, 234-242. Available from: doi:10.1177/036354657300100403.

13. Cui, W., Ostrander, L.E. \& Lee, B.Y. (1990) In Vivo Reflectance of Blood and Tissue as a Function of Light Wavelength. IEEE Transactions on Biomedical Engineering. [Online] Available from: doi:10.1109/10.55667.

14. Lee, J., Matsumura, K., Yamakoshi, K.I., Rolfe, P., et al. (2013) Comparison between red, green and blue light reflection photoplethysmography for heart rate monitoring during motion. In: Proceedings of the Annual International Conference of the IEEE Engineering in Medicine and Biology Society, EMBS. [Online]. 2013 p. Available from: doi:10.1109/EMBC.2013.6609852.

15. Anderson, R.R. \& Parrish, J.A. (1981) The optics of human skin. Journal of Investigative Dermatology. [Online] Available from: doi:10.1111/1523-1747.ep12479191.

\section{Figures}




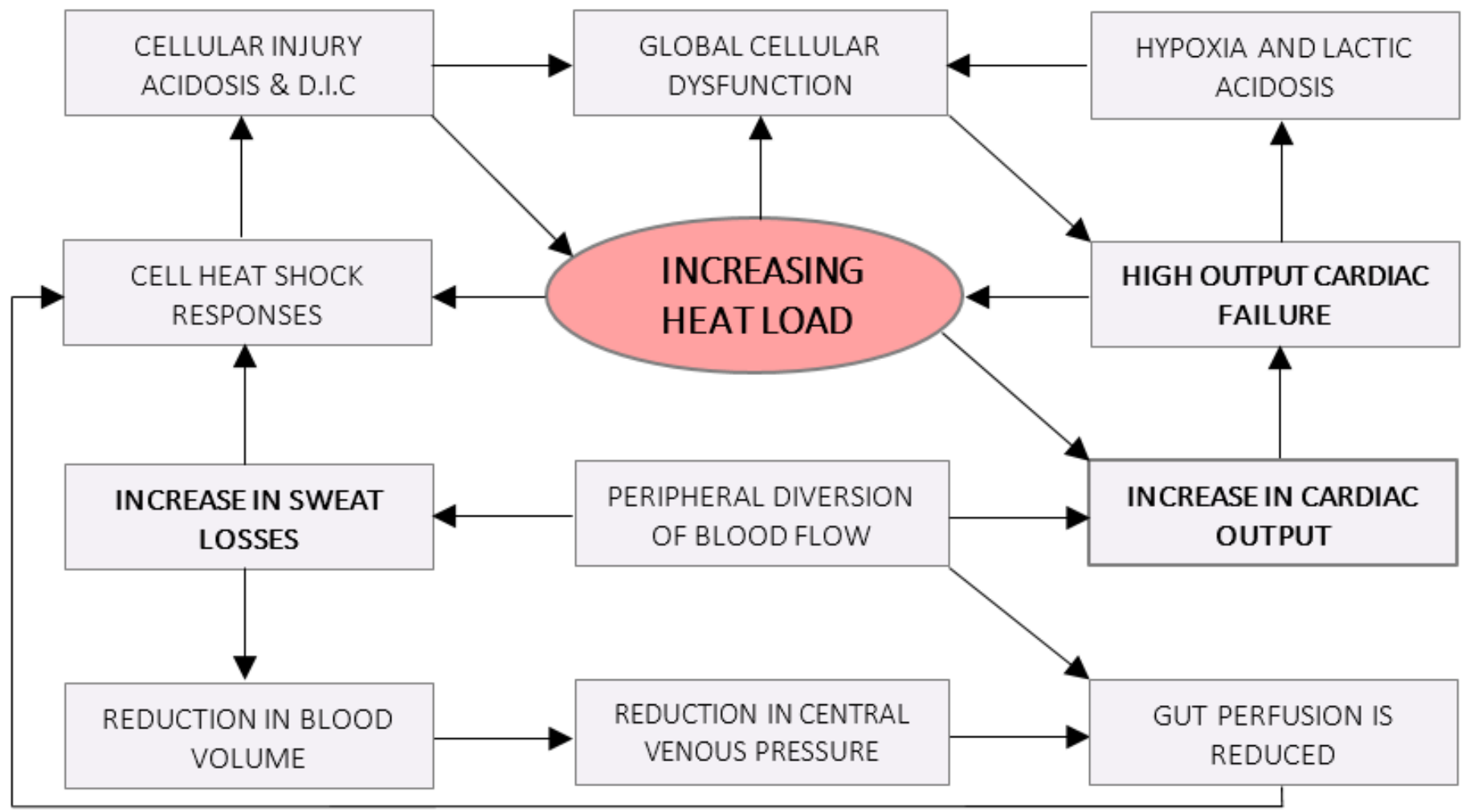

Figure 1

Abnormal pathophysiological responses occurring with loss of normal thermoregulation, as described and depicted by Hunt and Smith, 2005.

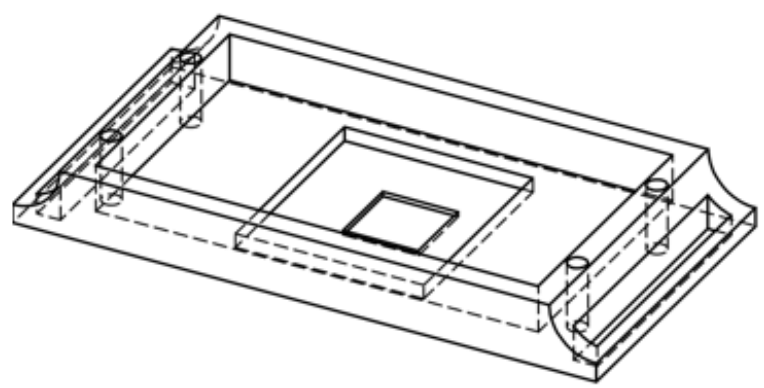

Trimetric View

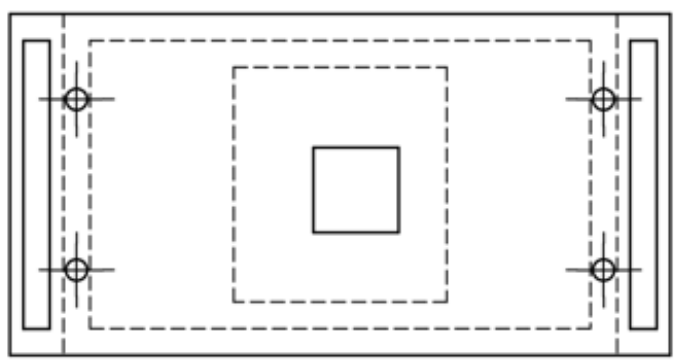

Bottom View

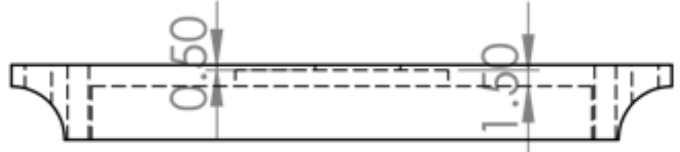

Projected Side View

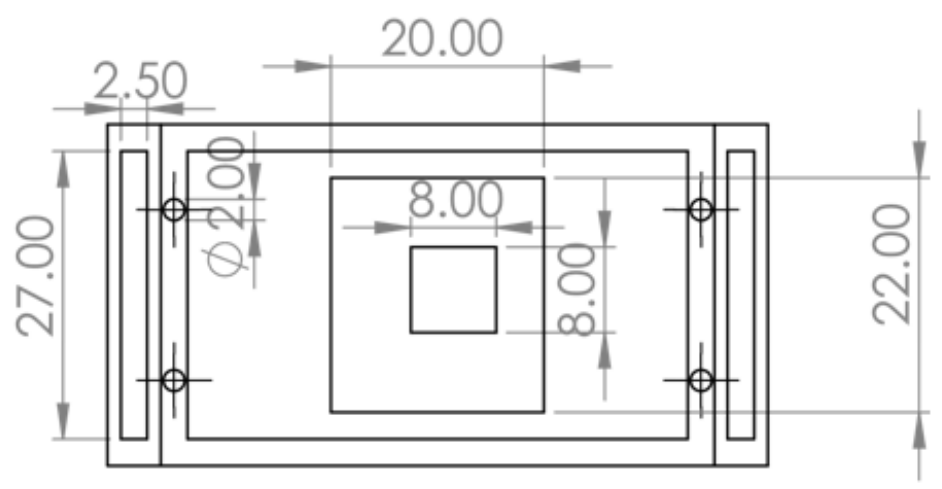

Top View

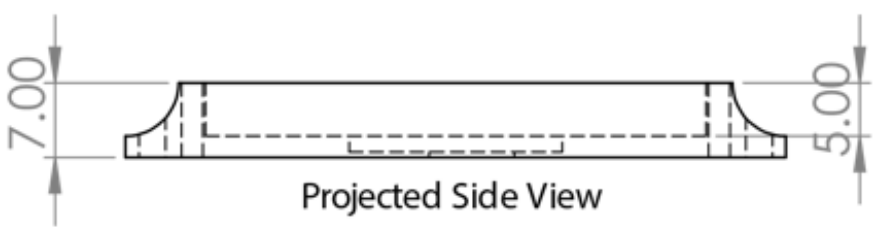


Figure 2

Bottom half of MAX30101 wearable case, units in $\mathrm{mm}$.

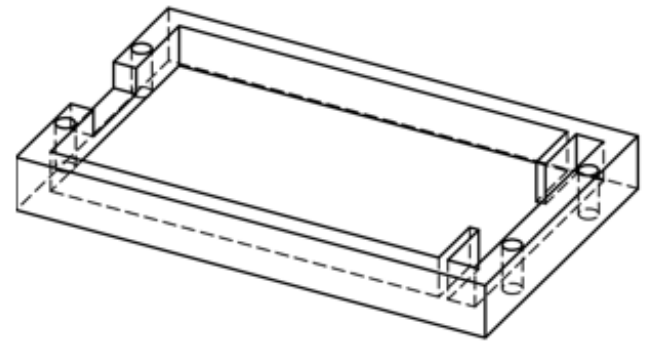

Trimetric View

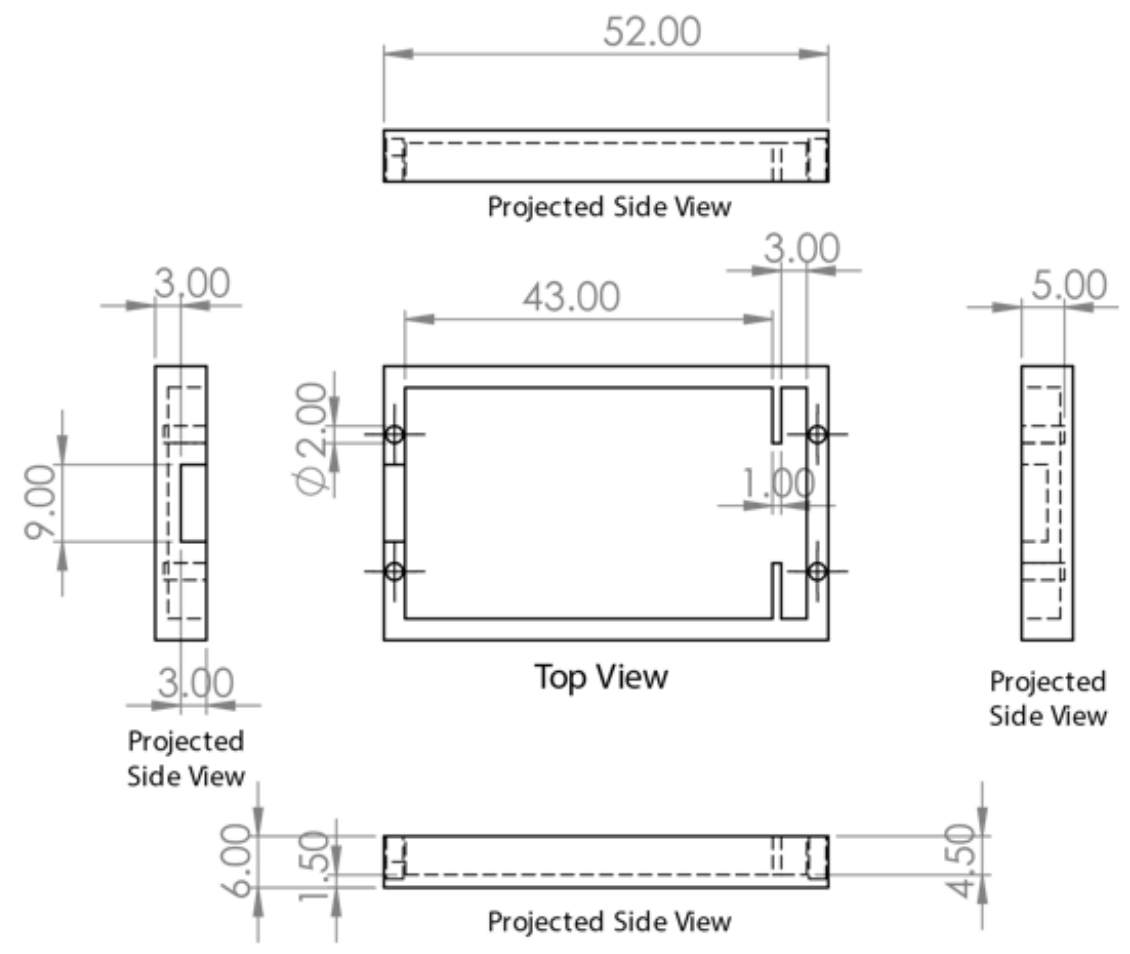

Figure 3

Top half of MAX30101 wearable case, units in mm.

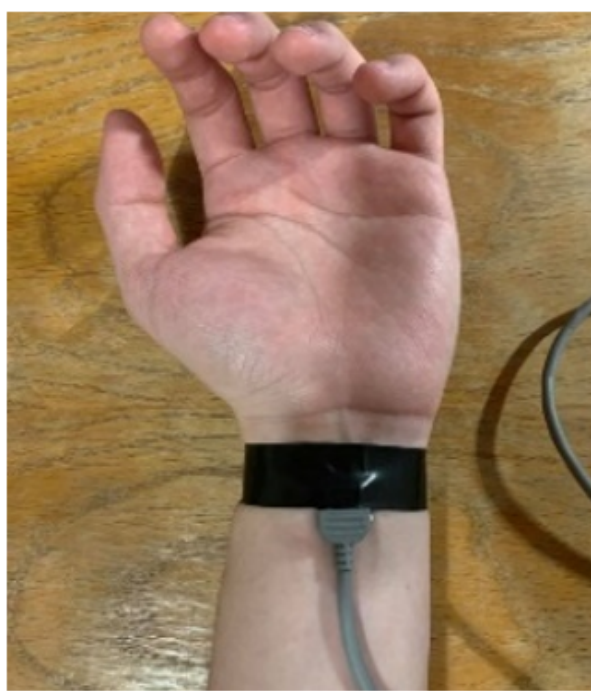

a) Anterior wrist

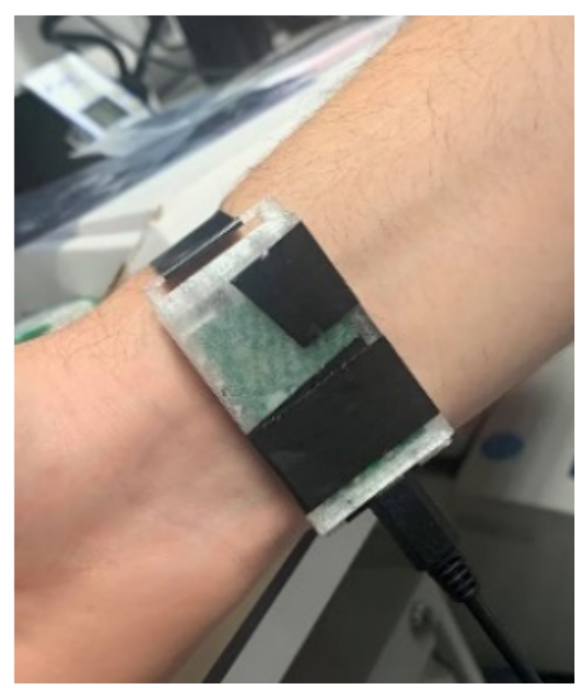

b) Anterior wrist with case

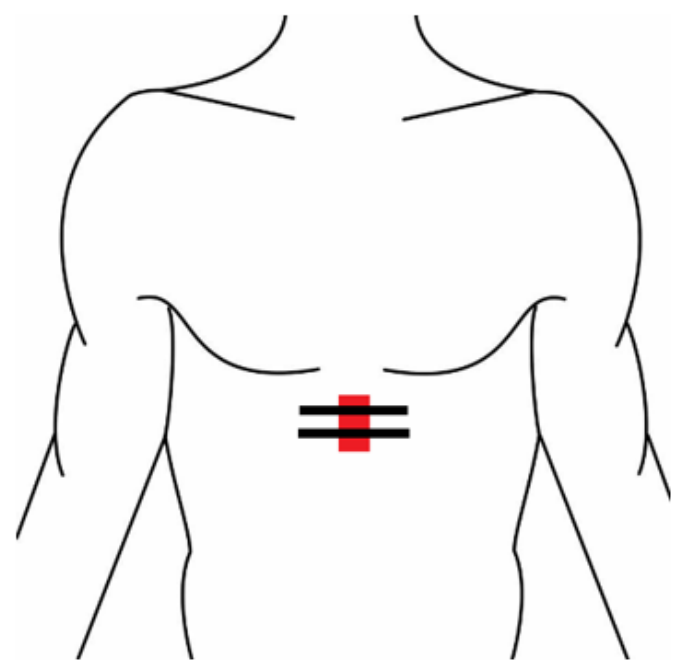

c) Chest

Figure 4 
Positioning of sensor for capturing PPG signal. a) Anterior wrist: Sensor secured $1 \mathrm{~cm}$ below wrist line in centre of wrist, secured by tape. b) Anterior wrist with case: Sensor secured $2 \mathrm{~cm}$ below wrist line in centre of wrist with watch-style straps securing case made of tape. c) Chest: Sensor secured in centre of chest directly below the sternum and secured using tape.

NOISE REMOVAL

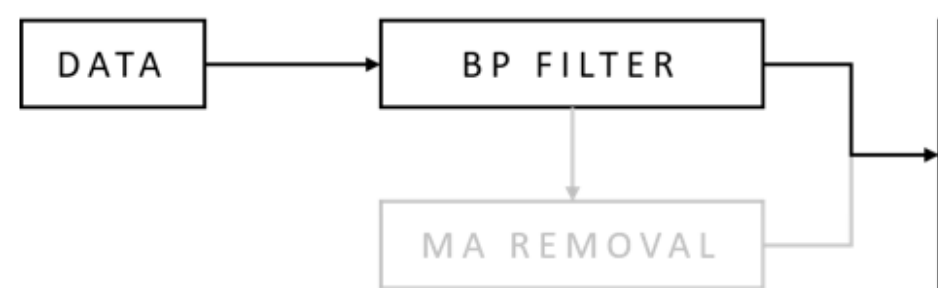

INTERVAL

ESTIMATION

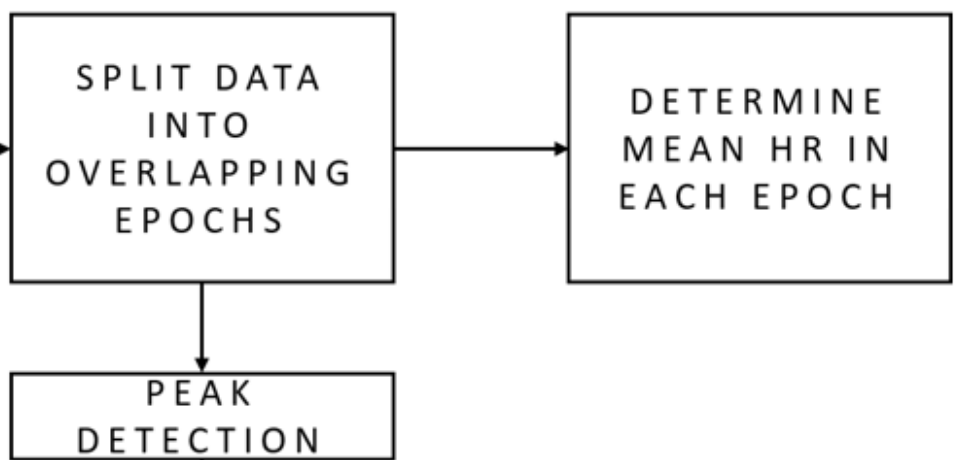

\section{Figure 5}

Heart rate estimation algorithm framework utilising raw PPG data input, each block representing different processing steps. (In grey: motion artefact removal - not included in current algorithm).

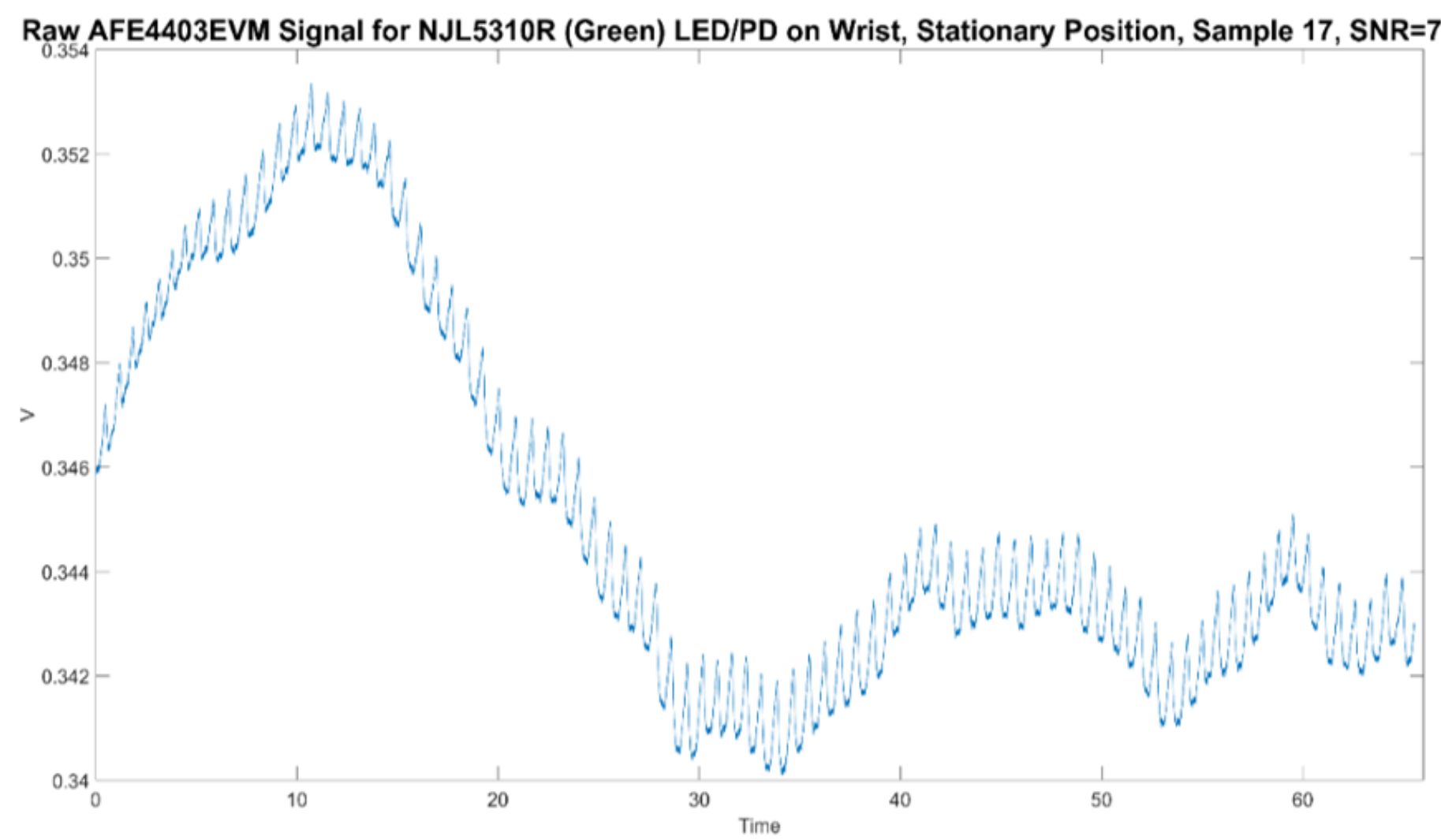


Figure 6

Example raw PPG waveform from AFE4403EVM with NJL5310R green LED/PD on anterior wrist, stationary position. SNR $=72.89$

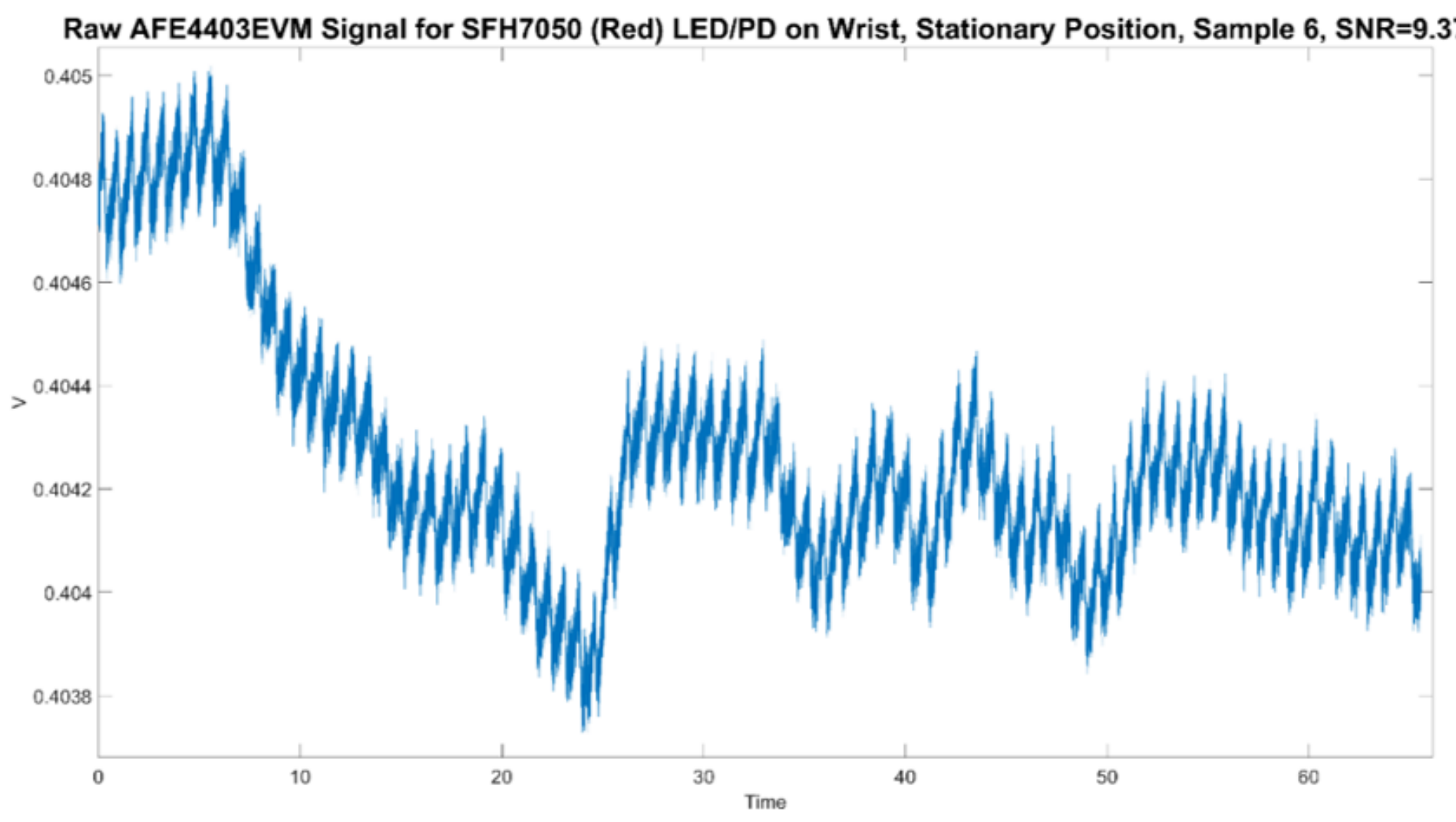

Figure 7

Example raw PPG waveform from AFE4403EVM with SFH7050 red LED/PD on anterior wrist, stationary position. SNR=9.37. 

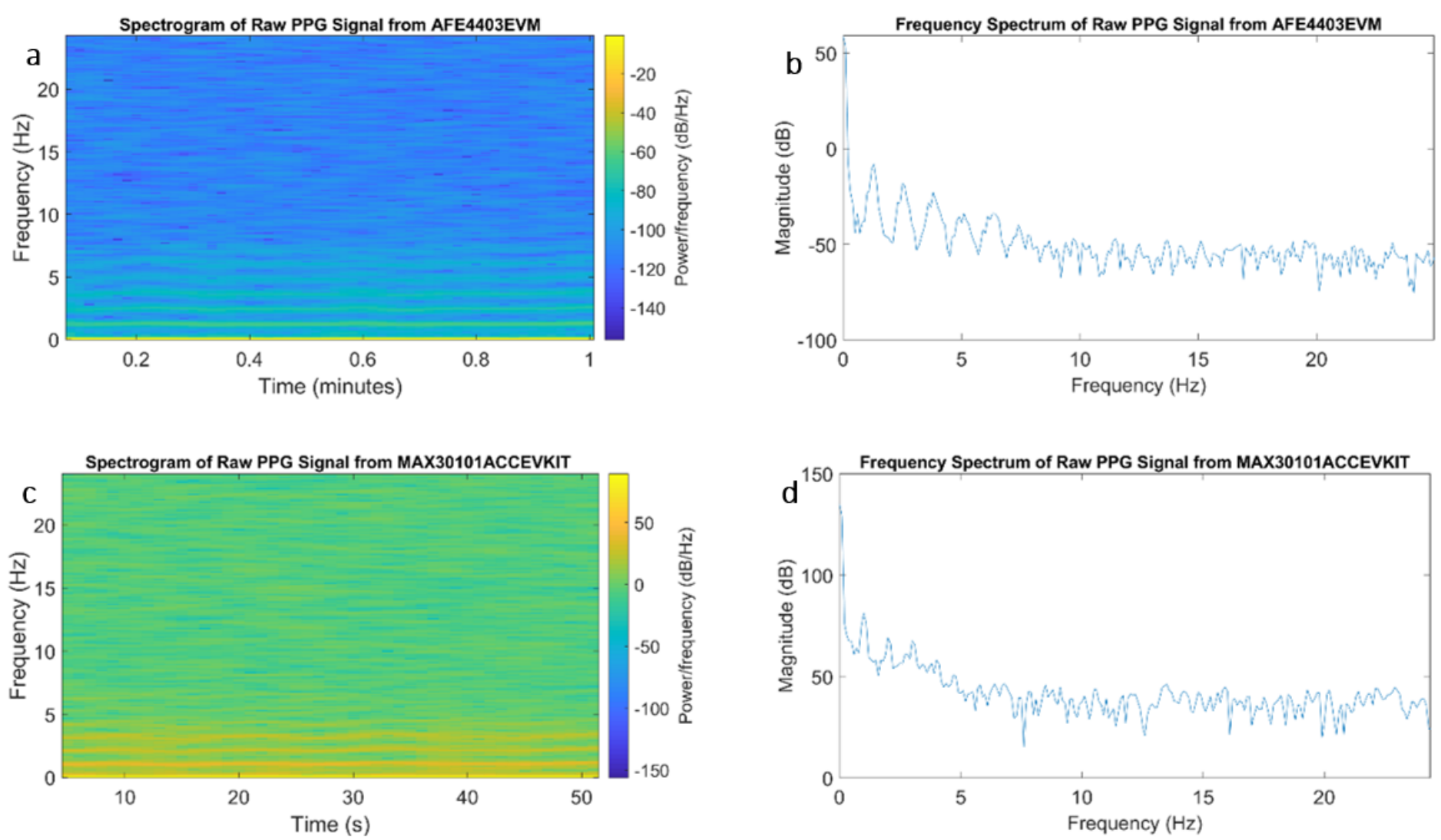

Figure 8

a) Spectrogram of raw PPG signal obtained from AFE4403EVM with NJL5310R, $\lambda=525 \mathrm{~nm}$, generated using short-time Fourier transform with a rectangular window of 5000 samples with 4500 sample overlap, sampled at $500 \mathrm{~Hz}$. b) Frequency spectra of 1 second segment of the same PPG signal. c) Spectrogram of entire raw PPG signal obtained from MAX30101ACCEVKIT with MAX30101 integrated green optical sensing module, $\lambda=537 \mathrm{~nm}$, generated using a rectangular window of 1000 samples with 900 sample overlap, sampled at $100 \mathrm{~Hz}$. d) Frequency spectra of 1 second segment of the raw PPG signal from MAX30101ACCEVKIT with MAX30101 generated using short-time Fourier transform. 
Raw AFE4403EVM Signal for Green LED/PD on Wrist, Periodic Running Motion
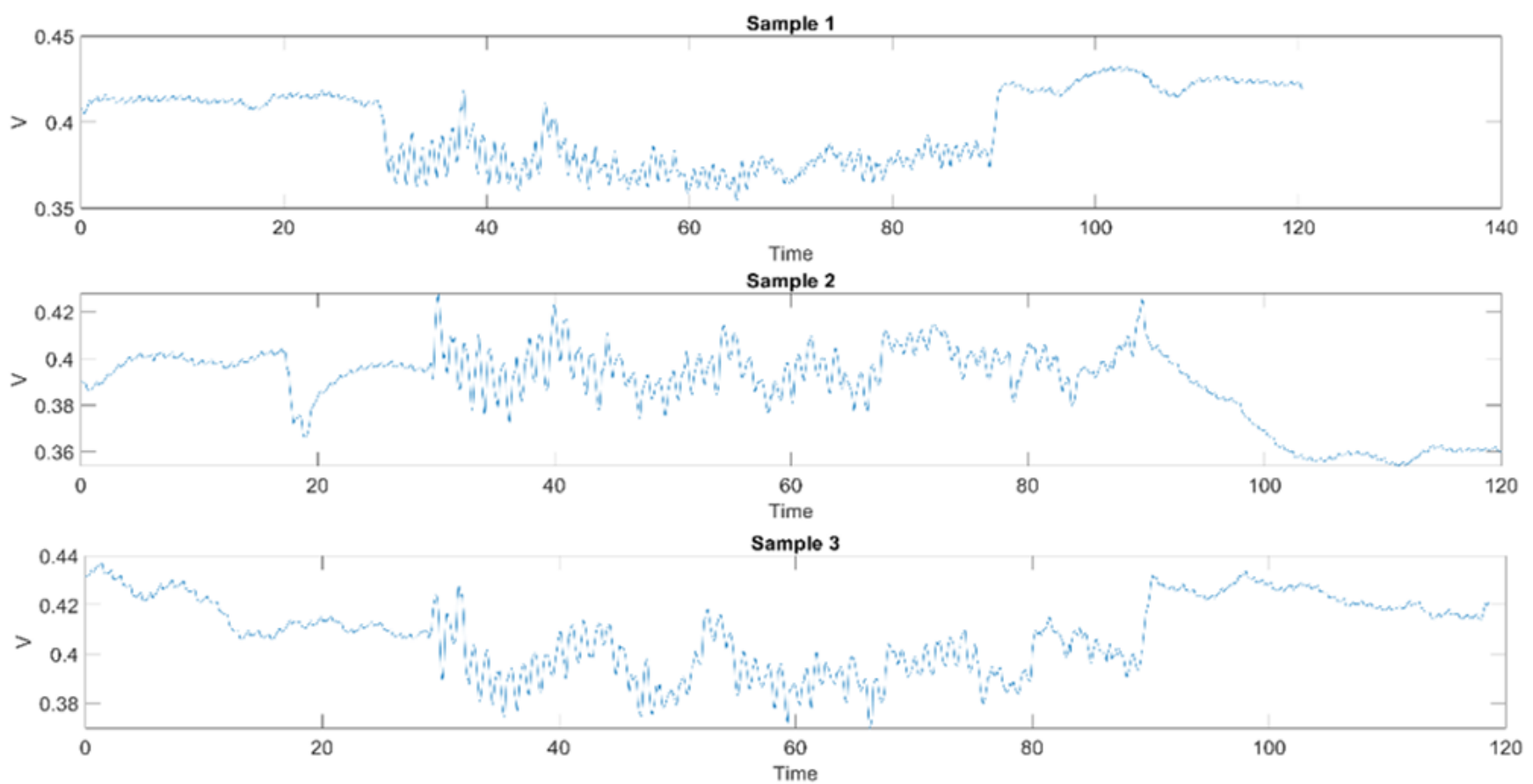

Raw AFE4403EVM Signal for Green LED/PD on Wrist, Non-Periodic Running Motion
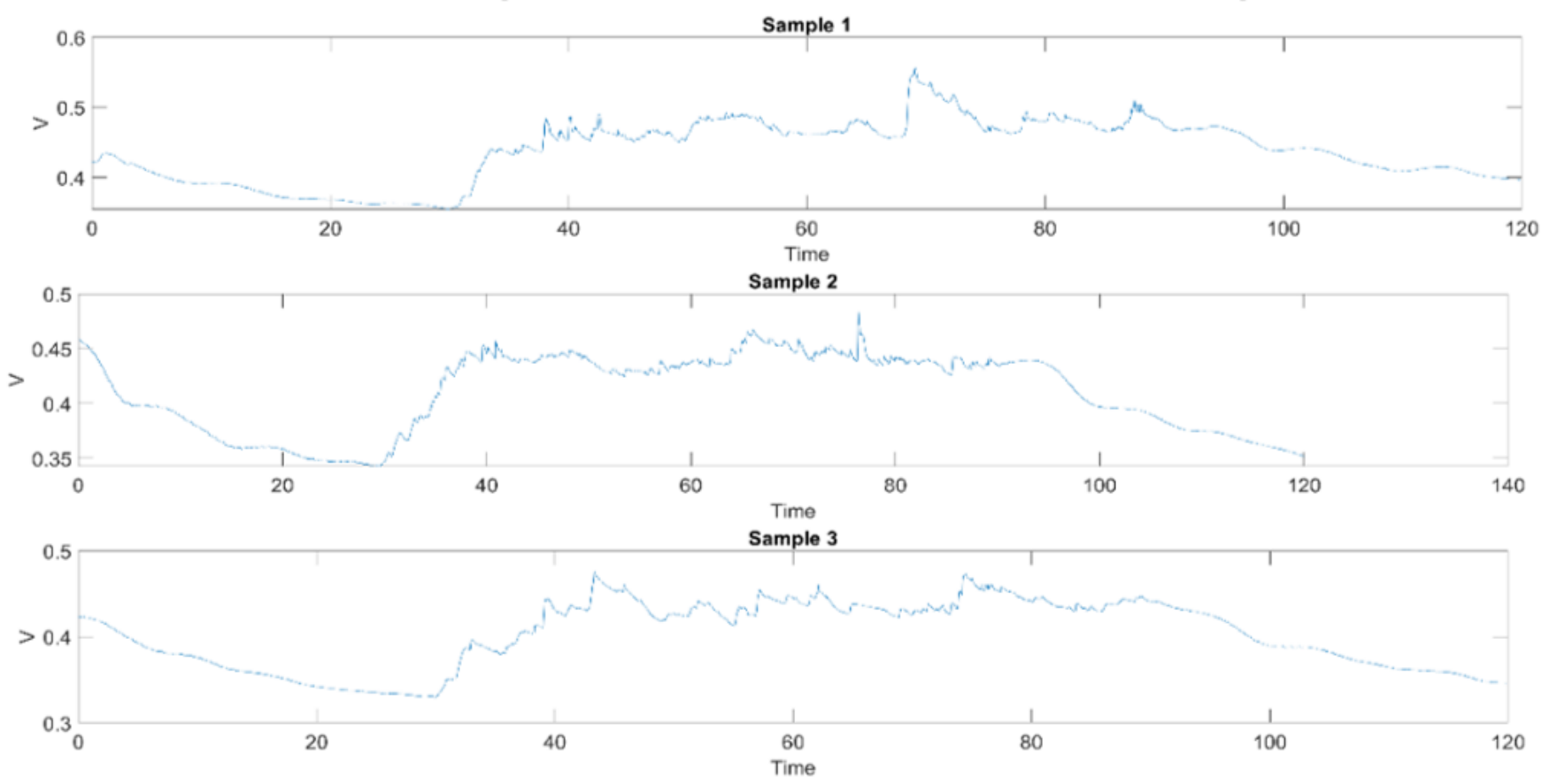

\section{Figure 9}

Raw PPG waveform from AFE4403EVM with NJL5310R green LED/PD on anterior wrist during periodic (top) and non-periodic (bottom) running arm swing motion. 
Frequency Analysis of Raw PPG Signal from AFE4403EVM during Periodic and Non-Periodic Ulnar Deviation
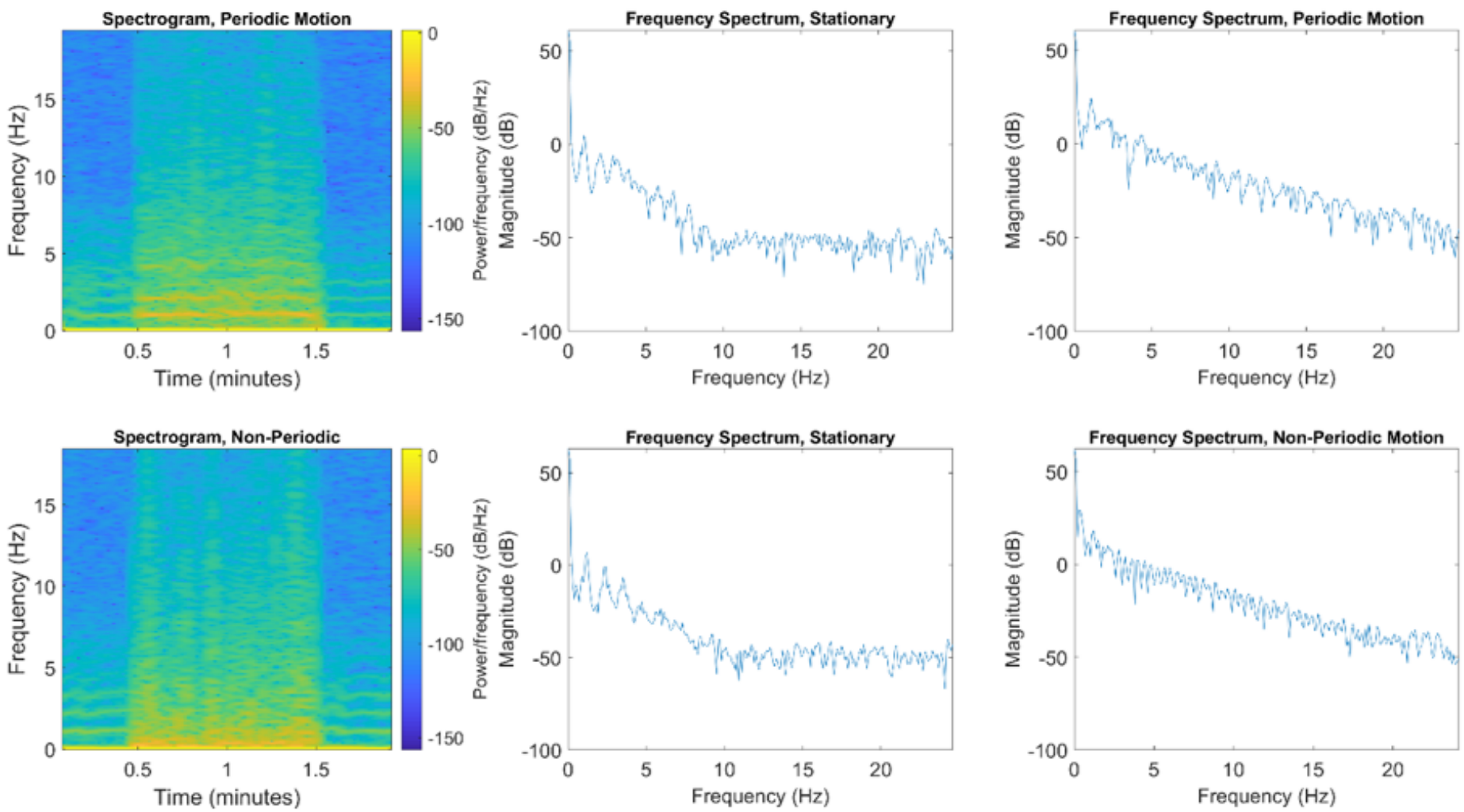

Figure 10

Spectrogram and frequency spectra of raw PPG obtained from AFE4403EVM with NJL5310R, $\lambda=525 \mathrm{~nm}$, for periodic (top) and non-periodic (bottom) ulnar deviation. The spectrogram was generated using shorttime Fourier transform with a rectangular window of 5000 samples with 4500 sample overlap, sampled at $500 \mathrm{~Hz}$. The frequency spectra were taken from a 1 second segment of the raw PPG signal while stationary ( $\mathrm{t}=20 \mathrm{~s})$ and during motion $(\mathrm{t}=60 \mathrm{~s})$. 


\section{HR Estimation from PPG against Reference HR (ECG)}

Correlation between Estimated $\mathrm{HR}$ and Reference HR

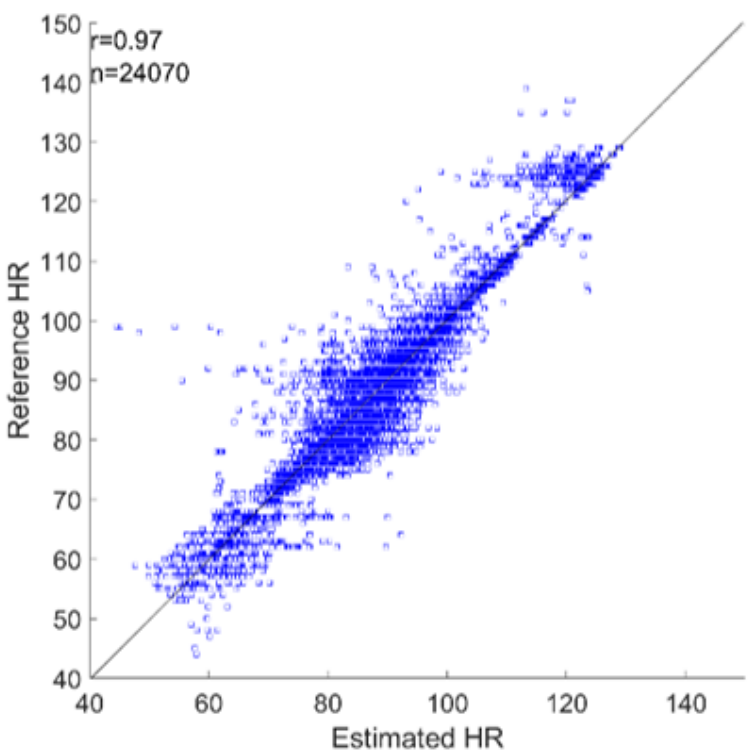

Agreement between Estimated HR and Reference HR

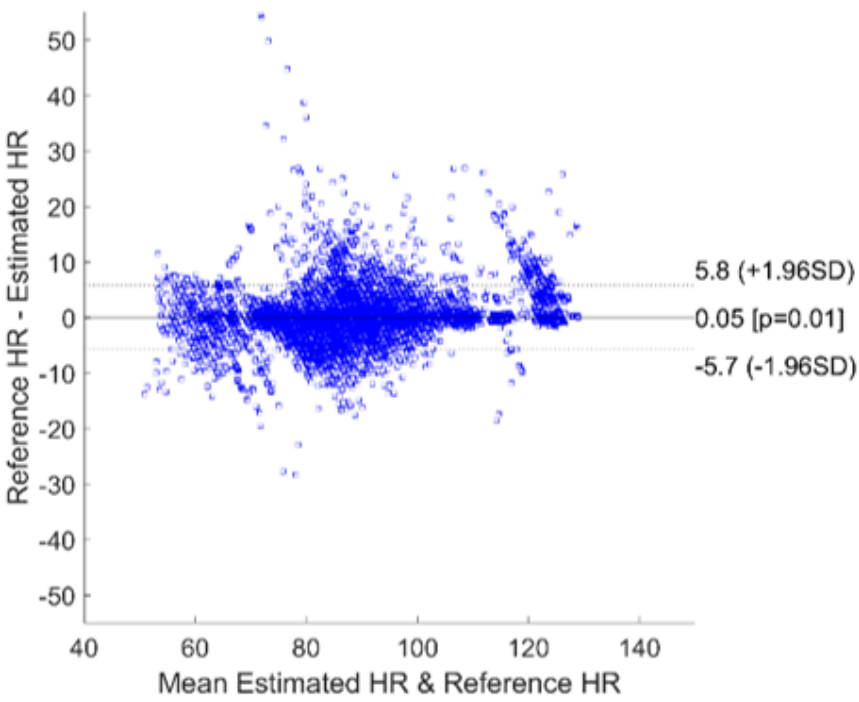

\section{Figure 11}

Correlation (left) and Bland-Altman agreement plot (right) between estimated and reference HR Comparison of HR Estimates for AFE4403EVM PPG and Apple Watch
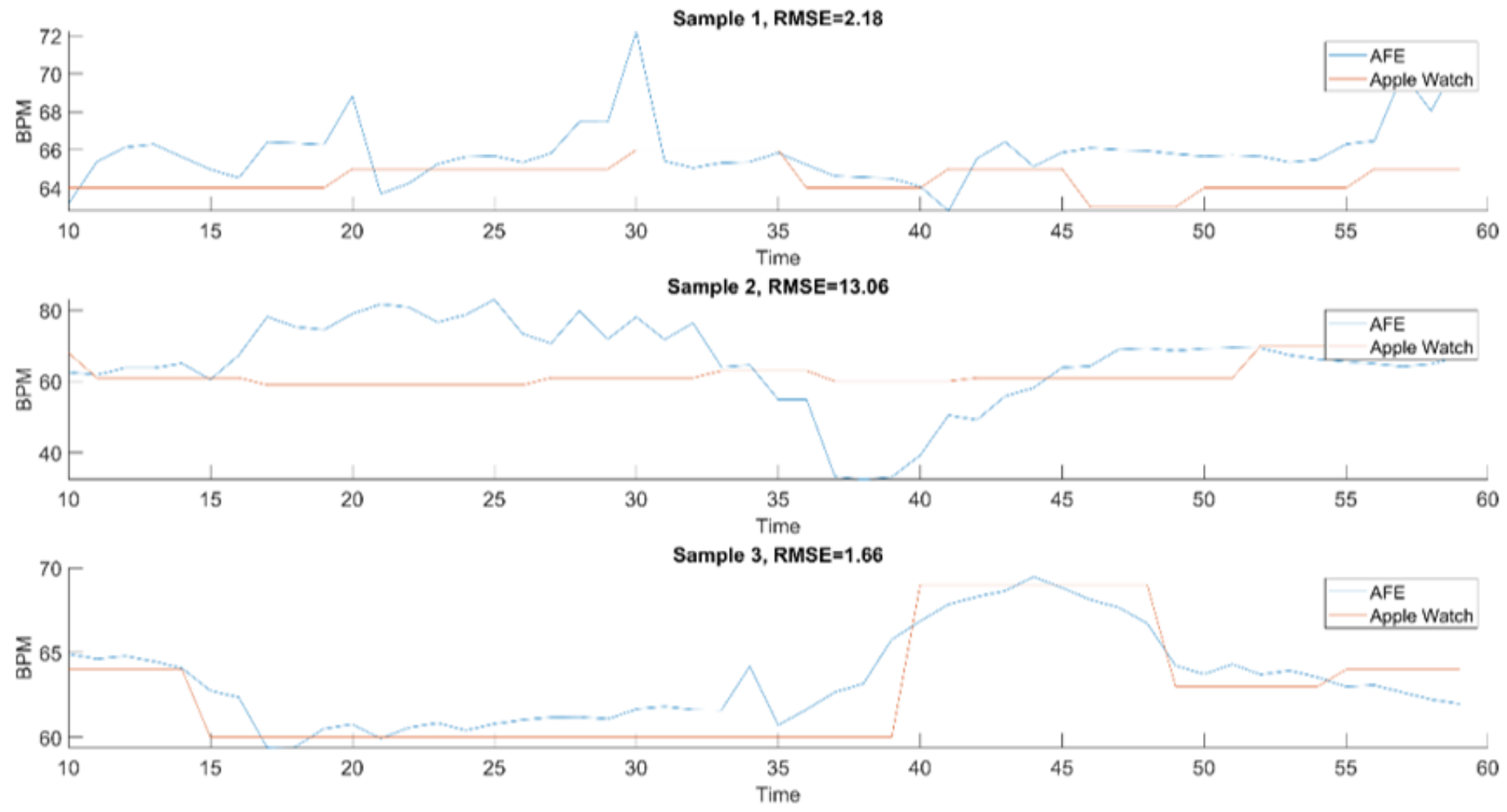

Figure 12 
Comparison of HR estimated using the proposed algorithm on raw PPG waveforms measured with AFE4403EVM and HR estimates from the Apple Watch Series 5.

\section{HR Estimation from PPG against Reference HR (ECG) during Run}
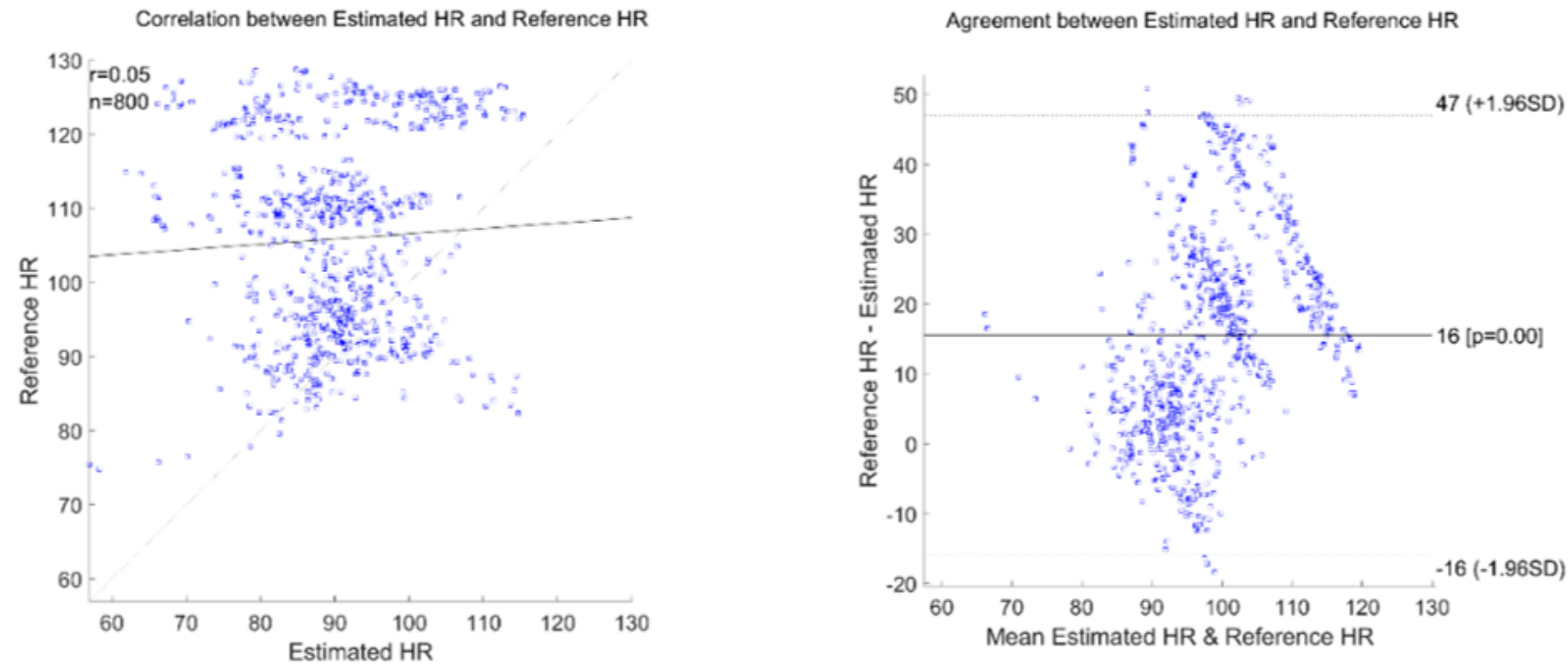

Figure 13

Correlation (left) and Bland-Altman agreement plot (right) between estimated and reference HR during run.

\section{HR Estimation from PPG against Reference HR (ECG) during Walk}

Correlation between Estimated HR and Reference HR

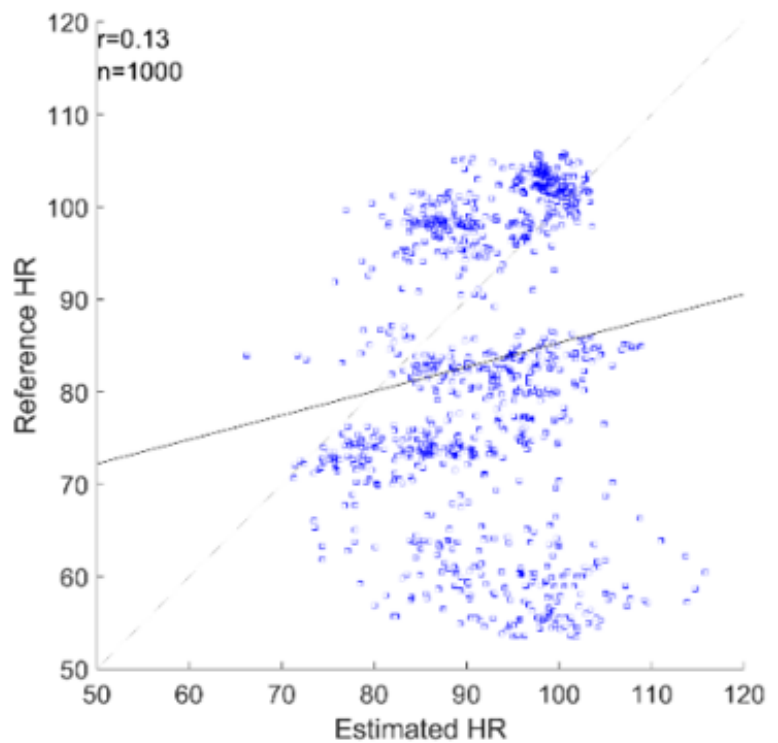

Agreement between Estimated HR and Reference HR

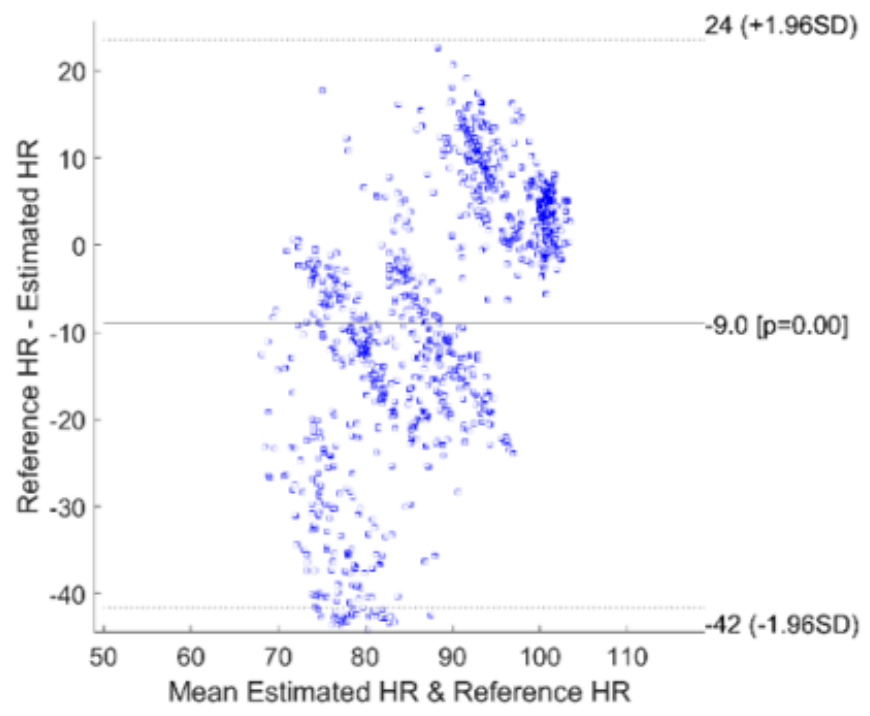

Figure 14 
Correlation (left) and Bland-Altman agreement plot (right) between estimated and reference HR during walk. 